\title{
Time As an Allay Of Attenuating Stress to Ameliorate Employee Performance
}

\author{
Ekta Chakravarty \\ M.Com $4^{\text {th }}$ Semester Gauhati Commerce College, Gauhati University "Solace", House No-8, $3^{\text {rd }}$ Floor, By \\ Lane-2, Shreenagar, Dispur P.O, Guwahati-5, Pincode-781005, Guwahati, Assam, India
}

\begin{abstract}
Time is the factor under which everything runs. Growth to end of any material or non material depends on time. It may sound platitudinous but is nevertheless true that a country that wants to make economic progress must be wedded to the doctrine of the organisational growth. Economic progress is not possible without it. However, much organisational development is cherished and achieved still various complex problems do arise in the field of the employees and their performance. The dynamics such as group behaviour, team building, organisational conflicts and negotiation, communication, job frustration, power and policies gives birth to the psychological term stress. Stress is simply a fact of nature -- forces from the inside or outside world affecting the individual. Because of the nimiety of stress in the modern lives, the thought follows a negative experience. The biological view of stress on the other hand can be a neutral, negative, or positive experience. The purpose of this study was to examine whether time management behaviours moderated relations between stressors and strain. It was further predicted that the use of time management behaviours would attenuate stress-strain relations. Data collected from 346 employers constituted both men and women and indicated the use of time management behaviours as an allay to stress attenuation. The relations between the stress and strain to be reduced by time management were partially mediated by feelings of control over time.

Keywords: employee, performance, strain, stress and time
\end{abstract}

\section{Introduction}

Stress is a phenomenon that manifests in the individual person as a result of various stressors that arise from the self and the environment and affect the individual person in accordance with the way in which he or she attributes meaning to the events and in accordance with the way in which he or she experiences and enters into or handles such events, stimuli or demands. The stress response is a normal psycho physiological response to stressful or traumatic events of environmental stressors and interpersonal conflicts experienced by individual. Stress holds a risk to health when its occurrence is frequent and mismanaged. Stressful events can pose a threat to both health and life. Though stress is not the primary cause, it is entangled in over half of all human morbidity and mortality. More than 20 years of occupational stress research has shown that stressful working conditions are associated with poor mental and physical health. Such effects may serve to increase organizational healthcare costs, impair employees' performance and generally make for a poorer quality of work life.

Lack of time is a common complaint in organisational society. In response, there has been a procreation of books, articles, and seminars on time management, along with their assertions and anecdotes. But what exactly is time management remains a research. Despite the epidemic of time management training programs there is currently a lack of agreement about the definition of time management and a dearth of literature summarizing time management across disciplines. Although self report instruments purporting to examine time management exist in several peripheries, to date, there has been no published stress review or comparison of the psychometric instruments for assessing generic time management.

This study thus attempts to examine the existing time management to allay stress and strain and enhance the employee performance.

The researcher further step to put forward ways of attenuating stress and seeks further suggestion to help employee benefited by time management.

\section{Objectives}

A study is been conducted and the objectives of them are:

1. To describe the current state of time management and the rationale for time management training.

2. To delineate the skills and behaviours associated with time management identified in the industrial, administrative, management and coaching domains.

3. To investigate whether time management moderate the relationship between stressors and strain. 


\section{Methodology}

The methodologies employed in determining the data are based on both primary and secondary data. A questionnaire was employed as it allows the researcher to gather structured information from a large number of individuals and it allows for anonymity and it is economical to use. The primary data is been collected from the nearby area of in Balaji, Borjhar, Chandmari, RBI- Guwahati, Panbazar, Zoo Road and Bara Service area that participated in the research study. The researcher personally delivered the questionnaires to the respondents, at which instance an agreed upon collection date was determined; in most cases it was a week after the distribution of the questionnaire. The methods implemented for collecting primary data were observation, telephonic communication, interview and distribution of electronic questionnaire in the cities mentioned. Secondary data is based on journals, magazines, newspapers and web. A cover letter explaining the purpose of the research and assurance of confidentiality of the respondents' identity accompanied each questionnaire.

\section{Findings}

Description of the current state of time management and the rationale for time management training as per the first objective are:

1. $36 \%$ of the respondents believed time management is a habit.

2. $28 \%$ of the total respondents believed that goal helps time management.

3. $24 \%$ of the total respondents believed situation is the best trainer of time management.

4. $12 \%$ of the total respondents believed time analysis helped describe the current state of time management and the rationale for time management training.

As per the second objective, to delineate the skills and behaviours associated with time management are:

1. $56 \%$ of the total respondents are in the view that leadership describes the relation of time management.

2. $28 \%$ of the total respondents are in the view that job performance appreciation describes the skill and behaviour of an employee.

3. $16 \%$ of the total respondents are in the view that self reports describes the relation of time management by delineating the skills and behaviours identified in the industrial, administrative, management and coaching domains.

Investigation to whether time management moderate the relationship between stressors and strain as per the third objective are:

1. Moderating effect of mechanics of time management indicated that this dimension of time management moderated only the relation between work-family conflict and strain by $40 \%$ of the total respondent.

2. Role overload is viewed as a factor reduced by time management by $23 \%$ of the total respondent.

3. Feelings of control by $20 \%$ of the total respondent as a factor reduced by time management

4. Prioritization moderates the relationship between stressors and strain with time management by $17 \%$ of the total respondents.

\section{Analysis}

Time management has been described using many different terms including spontaneity, equilibrium, flexibility, and having control over time. Time management has also been characterized as a habit developed only through determination and, as prioritizing and respecting those priorities and as setting priorities and scheduling tasks. Time management can also be considered as the process by which an individual more effectively accomplishes tasks and goals, a process by which an individual obtains control over the timing and the content of what he/she does, and as what can be accomplished with time. In order to utilize time efficiently, individuals must possess the ability to predict how much time is needed for the activity. An individual will become effective in using their time only when the individual clearly have an idea of the doings, the needs for the action, and for which specific target date. Individuals need to become more disciplined in their use of time by respecting their established priorities while minimizing distractions from others as well as from situations that have the ability to displace priorities in terms of time and energy. According to Crutsinger (1994), time management involves determining the reason for goal setting, deciding important events and realizing that other activities will have to be scheduled around them, making decisions for the time to be utilised for certain tasks, adjusting to the unexpected situations and reconsidering goals and priorities on a regular basis and observing patterns and trends in behaviour. Time management behaviours have more recently been characterized as making lists, organizing, goal setting, keeping and routine evaluation of one's schedule, and dividing tasks into simpler parts. Empirical research investigating the effects of time management behaviour has identified three broad clusters of behaviours. However, seven time management skills or behaviours can be considered essential to effective time management due to their repetitive prominence in the literature: (a) time analysis, (b) planning, (c) goal setting, (d) prioritizing, (e) scheduling, (f) organizing, and (g) establishing new and improved time habits. 
The skills approach takes a leader-centred perspective on his leadership. In the skills approach we tend to shift the thinking from a focus on personality trait, which usually is viewed as innate to an emphasis on skills and abilities that can be learned and enhanced. Although personality plays an important role in leadership, this approach suggests that knowledge and abilities are needed for effective leadership. Technical skill is knowledge about and proficiency in a specific type of activity. It includes aptitude in a specialized area, analytical ability to use appropriate tools and techniques. Human skills are "people skills." They are the dexterity that helps a leader to work effectively with subordinates, superiors and peers to complete the organization's goals. Human sleights allow a leader to assist members in working cooperatively as a group to achieve common goals. Being a leader with human skills is being sensitive to the needs and motivations of others and taking into account others' needs in one's decision making. Thus we can say that human ability is the capacity to get along with others as we go about our work. Conceptual skills are central to creating a vision and strategic plan for an organization. A leader with conceptual skills is comfortable talking about the ideas that shape an organization and the intricacies involved. He or she is good at putting the company's goals into words and can understand and express the economic principles that affect the company. A leader with conceptual skills works easily with abstractions and hypothetical notions.

Performance as regarded to behaviour as something done by the employees. The concept differentiates performance from conclusion. Conclusions are the result of an individual's performance and other influences. However, there are more factors that determine outcomes than just an employee's behaviours and actions. Exceptions remain when defining performance as behaviour. Mental productions such as answers or decisions, performance needs to be under the individual's control, regardless the performance of interest is mental or behavioural. The difference between individual controlled action and outcomes is best conveyed through an example. On a sales job, a favourable outcome is a certain level of revenue generated through the sale of idea or thing. Revenue generated depends on the behaviour of employees. Employees performance in this sales job well then he is able to move more merchandise. Another closely related construct is productivity. Utility is another construct that defines the value of a level of performance, effectiveness, or productivity. Dexterity of performance, effectiveness, and productivity are value judgments. Thus time management helps people accelerate performance and skill and behaviour is thus described by the way he performs.

The relationship between time management behaviours and other variables such as academic achievement, stress, and creativity, most studies were conducted with university or college student populations and most studies utilized some form of questionnaire or self-report measure to assess time management. Alternatives to self-report measures included self-reported time usage questions and observational checklists. Results from these studies showed that self-reports of time management behaviours or skills were often related to academic achievement; effective time management lower stress and strain; good time managers preferred planning and organization; older subjects and women engaged more frequently in planning and time management behaviours; individuals who indicated that they set goals and priorities tended toward the Type A behaviour pattern; and individuals who had previous time management training engaged more frequently in time management behaviours. In addition, inefficient time use, lack of control over time demands, and inadequate amounts of time appeared to have a negative impact on individuals' psychological resources.

The results of this study are consistent with recent research suggesting that engaging in time management behaviours may have a positive impact on the mental health of employees. These effects were rather modest, however, and suggest that the direct benefits of time management behaviour may be rather marginal. It was also found, consistent that the relation between time management behaviour and strain may depend upon its effect on feelings of control over time. Feelings of control only partially mediated relations between two dimensions of time management behaviour and strain. The findings regarding moderator effects were largely consistent that time management behaviour did not moderate the impact of role overload. The present study did show that all three forms of time management behaviour moderated the relation between work-family conflict and strain. These effects, however, explained a very small portion of the variance in strain. If employees engage in time management behaviours without attending formal training programmes, then learning such behaviours is problematic. It is possible that employees often seek out such training on their own, or perhaps some differences in the use of time management behaviours are simply due to stable individual differences. If either of these were the case, investing in time management training would have limited value.

\section{Suggestion}

The psychological skill helps a person to modify perceptions regarding events regarded as bad events and adversity, and to think positively rather negative. Individuals tend to develop either optimistic or pessimistic habits of thought with regard to life events. Optimistic thinkers focus on the benefits of good events and minimize the stressful aspects of bad events. The individuals view adversity as temporary, with limited bad effects, and something that is not their personal responsibility. On the other hand, pessimistic thinkers feel responsible for adversity and view it as more permanent and with wider-ranging consequences. The aim of 
learned optimism is to change the way of a person's view towards life events and making bad events less stressful while enhancing the experience of hope for the individual concerned.

Time management and planning are primary prevention skills that allow healthy achievement, while avoiding overload and a crisis management approach. Crisis managers create more stress both for themselves and for others around them. People who manage events in a broader context are macro time managers with skills to plan using this approach, helps people set and prioritize goals, create and execute plans, and then feel good about achieving results. Personal goals are as important as professional goals.

Modifying type A behaviour pattern and building supportive social relationships also help attenuate stress through time management as people help in managing one's time consciously or sub consciously.

\section{Conclusion}

A much simpler and less costly way to potentially lessen the impact of stressors is through the use of time management behaviours. Time management behaviour can be broken down into the following three dimensions:

(1)Goal setting and prioritization;

(2) Mechanics of time management; and

(3)Preference for organization.

The preference for organization dimension involves having an organized, methodical approach to work. Behaviour consistent with this dimension would be organizing one's desk before beginning work each day. Unfortunately, very little empirical research has examined the effectiveness of time management training programmes, or the relationship between time management behaviours and stress-related outcomes. This is unfortunate, given the widespread use and acceptance of the value of time management behaviours. Recently, however, three relatively rigorous empirical studies examining time management have been conducted. The use of time management behaviours was associated with lower levels subsequent depression, anxiety and physical symptoms. This study also examined whether time management behaviours moderated relations between role overload and strains. No support was found for moderator effects, although this may have been due to low statistical power since the sample size was rather low, thus further work is needed to know how time can help attenuate stress and strain.

Time management behaviour is essentially a form of active coping that may better employees from the effects of multiple or conflicting job demands by enhancing their preparedness. If employees manage their time well by prioritizing tasks, setting goals, and organizing their work environment they may be more likely to cope with stressors without experiencing adverse psychological and physical consequences.

\section{Reference}

Books and journal

[1]. Ad a m s , G. A., \& Je x , S. M. (1997).Con® rmatory factor analysis of the time management behaviour scale. Psychological Reports $, 80,225 \pm 226$.

[2]. Ad a m s , G. A., Ki n g, L. A., \& Ki n g, D. W. (1996). Relationships of job and family involvement, family social support, and work-family con $^{-}$ict with job and life satisfaction. Journal of Applied Psychology, 81, 411 420 .

[3]. Ag u i n i s , H., \& St o n e -Ro m e r o, E. F. (1997). Methodological artifacts in moderated multiple regression and their eVects on statistical power. Journal of Applied Psychology , 82, $192 \pm 206$.

[4]. Atkinson, D, (2001). The time crunch. American Fitness, 19 (3), p. 37.

[5]. Barli n g, J., Ke 11 o w a y, E. K., \& Ch e u n g, D. (1996). Time management and achievement striving interact to predict car sales performance. Journal of Applied Psychology , 81, 821 826.

[6]. Britton, B. K., \& Glynn, S. M. (1989). Mental management and creativity: A cognitive model of time management for intellectual productivity.

[7]. Ca p 1 a n , R.D. (1971). Organizational stress and individual strain : A social-psychological study of risk factors in coronary heart disease among administrators, scientists, and engineers. (University micro® lms No. 72014822.)Institute for Social Research,University of Michigan.

[8]. Drawbaugh, C. C. (1984). Time and its use: A Self-management guide for teachers.

[9]. Foust, J. (2000). Dewey need to be organized? Time management and organization from a librarian who knows whereof she speaks! Book Report, 19, (2), 20.

[10]. Ga n s t e r , D. C., \& Sc h a u b r o e c k , J. (1991).Work stress and employee health. Journal of Management ,17, 235 \pm 271

[11]. Hellsten, L. M. (2005). The development and validation of a time management scale for exercise adoption, participation, and adherence. Doctoral thesis, University of Alberta, Canada.

[12]. Je x , S. M. (1998).Stress and Job Performance : Theory, Research, and Implications for Managerial Practice

[13]. Landy, F. J., Rastegary, H., Thayer, J., \& Colvin, C. (1991). Time urgency: The construct and its measurement. Journal of Applied Psychology, 76, 644-657.

[14]. Parry, S. B. (1985). Managerial assessment of proficiency MAP. Tucson, AZ: Training House Inc.

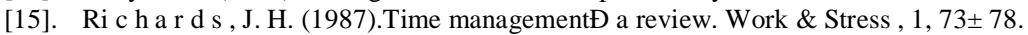

[16]. Simons, D. J., \& Galotti, K. M. (1992). Everyday planning: An analysis of daily time management. Bulletin of the Psychonomic Society, 30, (1), 61-64.

[17]. Trueman, M. \& Hartley, J. (1995). Measuring time-management skills: a cross-cultural study.

[18]. Zinatelli, M., Dube, M. A., \& Jovanovic, R. (2002). Computer-based study skills training: The role of technology in improving performance and retention. College Student Retention, 4, (1), 67-78. 


\section{Webiography}

1. http://www.acefitness.org/fitness-certifications/pdfs/LWMC-Exam-Content-Outline.pdf

2. http://www.sagepub.com/upm-data/45968 Chapter 3.pdf

3. http://en.wikipedia.org/wiki/Job_performance

4. http://cdn.intechopen.com/pdfs/33747/InTechWhat_do_we_know_about_time_management_a_review_of_the_literature_and_a_psych ometric critique of instruents assessing time management.pdf

5. http://www.managementbyarts.com/

6. $\quad$ http://educabilia.in/business-entrepreneurship/q/time-management $\underline{\text { skills?eq=time+management+skills\&g=management+skills\&gclid }=C I r c x 5 \text { mylbcCFY0s6wodKWEAaQ }}$ 